\title{
Algunos rasgos del comportamiento religioso de los militares españoles en época austriaca: el ejemplo de La Coruña
}

\author{
María del Carmen Saavedra Vázquez *
}

Pese a los sustanciales avances experimentados durante los últimos años en el estudio de la actividad militar y de los individuos encargados de sostenerla, ciertos aspectos del tema continúan sumidos en un importante desconocimiento debido básicamente a la lenta incorporación a esta vertiente de la historia política de los modelos y metodologías de uso común en otras ramas de la investigación histórica ${ }^{1}$. Esta realidad cobra su auténtico significado cuando se hace referencia a cuestiones de índole social, pero sobre todo cuando se trata de penetrar en el complejo mundo de las mentalidades colectivas para períodos anteriores a la época borbónica. Así la escasez de fuentes documentales de carácter específico relativas a los siglos XVI y XVII y las dificultades inherentes a cualquier intento de serialización de las mismas han contribuido a diseñar un panorama tan parco en resultados como sugerente de cara al futuro ${ }^{2}$.

* Universidad de Santiago de Compostela

Para obtener una panorámica de conjunto sobre la evolución de la historiografía militar europea vid. PIERre, P., "Sur les dimensions de I'histoire militaire", Annales, núm. 4-6 (1963), págs. 625-639; PARET, P., "The history of war», Daedalus, Vol. 100, núm. 2 (1971), págs. 376396; MARTEL, A., "Le renouveau de l'histoire militaire en Francem, Revue Historique, num. 497 (1971), págs. 107-126; Convisier, A., "Aspects divers de l'histoire militaire", Revue d'histoire moderne et contemporaine, T. XX (1973), págs. 1-9; HOWARD, M., La guerra en la historia europea. México 1983. En relación con el caso español, vid. Ribot GARciA, L. A., «El ejército de los Austrias. Aportaciones recientes y nuevas perspectivas", Pedralbes, núm. 3 (1983), págs. 89126 y SAAVEdRA VÁzQUez, M. C., "De la "historia de batallas" al "impacto de la guerra": algunas consideraciones sobre la actual historiografía militar española", Obradoiro de historia moderna, núm. 1 (1992), págs. 207-221.

2 Si prescindimos de algunos trabajos de carácter general orientados hacia el análisis de la mentalidad social que con respecto a los militares reflejan los tratados de la época, el grueso de las investigaciones sobre sociedad militar se ha centrado en unidades concretas del ejército 
De forma tradicional la historiografía que se ha venido ocupando del tema ha tratado de resaltar aquellas peculiaridades capaces de convertir a los militares en un grupo aparte, sostenido sobre códigos de conducta particulares que enfatizan su cohesión y favorecen su alejamiento con respecto a la sociedad en su conjunto ${ }^{3}$. Aunque resulta innegable que diversos factores de índole interno, y sobre todo la posesión de un fuero específico, otorgaban a este grupo social un carácter distintivo, más difícil resulta determinar la incidencia real de este elemento cuando se desciende al ámbito de lo individual y de las prácticas cotidianas. En este sentido no debemos olvidar que la Europa de los siglos XVI y XVII todavía permitía una continua interpenetración entre «lo civil» y «lo militar», pese a la diversificación profesional iniciada en el siglo $\mathrm{XV}^{4}$. La persistencia de las milicias populares y la extensión de la guerra en el continente habrian sido algunos de los factores favorecedores de dicho fenómeno, aunque en poco contribuyeran a mejorar la imagen de los militares generada por la literatura y las representaciones iconográficas de la época. De este modo los testimonios sobre la escasa moralidad y el bajo nivel cultural de las tropas iban a servir para caracterizar al soldado como un ser inestable, brutal y agresivo, un arquetipo que parece responder mejor a las características de los miembros de compañías itinerantes que a los de las guarniciones permanentes establecidas en el propio país ${ }^{5}$. La distinción entre ambos tipos de militares se revela, por lo tanto, crucial, y obliga a perfilar con claridad la naturaleza del grupo sujeto a investigación. A este respecto debemos recordar igualmente que en este período se estaba asistiendo a una importante transformación en el arte de la guerra y en el carácter de sus protagonistas. El triunfo del infante sobre el caballero no sólo haría posible el desarrollo de una ideología militar bifronte, sino

de tierra. Vid. Parker, G., El ejercito de Flandes y el camino español (1567-1659). Madrid 1976; CONTRERAS GAY, J., "La guarnición militar de la Alhambra en el siglo XVI", Anuario de historia moderna y contemporánea, núm. 7 (1980), págs. 7-23 y Quatrefages, R., Los Tercios. Madrid 1983.

3 En este sentido se han resaltado como caracteres propios de la sociedad militar el culto a la jerarquia y la creencia en un cierto número de valores ejemplares que enfatizan su espiritu de cuerpo - sentimiento del honor, patriotismo, emulación, etc.-. Cfr. HALE, J. R., War and Society in Renaissance Europe, 1450-1620. Leicester 1985.

${ }^{4}$ Tal circunstancia ha sido cumplidamente destacada por André Corvisier, considerando que la sociedad de este período estaba fuertemente impregnada por el espíritu militar. Vid. Corvisier, A., Armées et sociétés en Europe de 1494 a 1789. París 1976. En el caso español J. Antonio Maravall también se ha mostrado participe de dicha creencia y de situar en el siglo xV el inicio del proceso de separación entre vida civil y vida militar. Vid. MaravalL, J. A., Estado Moderno y mentalidad social (siglos xV-xVII). Madrid 1972, vol. 2, pág. 511.

5 Vid. Muchembled, R., La Violence au village (XV-XVIIsiècle). Sociabilité et comportements populaires en Artois du XV au XVII siècle. París 1989, pág. 109 y ss. 
Algunos rasgos del comportamiento religioso de los militares españoles...

también el surgimiento de un importante cambio de valores en dicho grupo social ${ }^{6}$.

Para el propósito que nos ocupa la cuestión fundamental consiste en el análisis comparativo entre el tipo de militar ideal perfilado por la tratadística y las fuentes literarias de la época y el militar verdadero caracterizado por su comportamiento concreto, sobre todo en el resbaladizo terreno de las actitudes religiosas. En el caso español tal planteamiento encuentra plena razón de ser dadas las consideraciones extendidas sobre algunas unidades de élite - como los Tercios-, cuya mentalidad se ha llegado a caracterizar por su "realce" de la "mentalidad normal española», con lo que ello supondría de "exasperación del sentimiento religioso, nacional, del honor y del valor" ${ }^{7}$. De este modo y aunque la consideración sobre los militares no recibe un tratamiento unívoco en el pensamiento de la época ${ }^{8}$, la identificación de la guerra con una actividad desarrollada en defensa de la religión y de la monarquía alcanza la primacía suficiente como para perfilar un modelo de soldado de moral intachable y probada virtud $^{9}$. En dicho contexto, el agudo contraste con la realidad no llegaría a empañar totalmente esa imagen del buen soldado, cuyas desviaciones de comportamiento suelen ser atribuidas a factores de índole diversa, como la falta de pagas, el sistema de alojamientos, la mala calidad de los capellanes al servicio del ejercito español, etc. En el mismo orden de cosas no debemos tampoco olvidar que la religión iba a ser utilizada como un elemento disciplinario, lo que explica el fomento por parte de las au-

- En ese nuevo código de valores del hombre de guerra coexistirán todavia durante largo tiempo las virtudes tradicionales - lealtad, caballerosidad, piedad hacia el enemigo derrotado, religiosidad, etc- con aquellas obras imprescindibles en el moderno arte militar -orden, sentido de la disciplina, prudencia o uniformidad-. Vid. PUDDU, R., El soldado Gentilhombre. Autorretrato de una sociedad guerrera: la España del siglo xvi. Barcelona 1984, págs. 72-94.

7 Bien es cierto que previamente se ha identificado el carácter español con tres constantes: "Sangre, sexo y muerte", lo que plantea serios interrogantes sobre ambos términos de la comparación. Vid. Quatrefages, R., Op. cit., pág. 409 y del mismo autor, "La elaboración de una nueva tradición militar en la España del siglo xvl», Cuadernos de Investigación histórica, núm. 4 (1980), págs. 7-16.

8 A título de ejemplo valgan las consideraciones que sobre la guerra y sus protagonistas hacía Antonio López de Vega a mediados de siglo xvil en sus «Paradojas Racionales». Según este autor, con las guerras "los únicos que salen ganando son los ociosos y perdidos, los bandidos con nombre de soldados y los maleantes de todo génerom, por cuanto la profesión de las armas vendría a ser una brutalidad indigna de hombres y el valor militar "se debe llamar antes fiereza que valor". Tomado de Martínez Arancón, A., La visión de la sociedad en el Pensamiento español de los Siglos de Oro. Madrid 1987, pág. 105.

- Amplias referencias a esta cuestión pueden encontrarse entre los principales tratadistas hispanos, como Pacheco de Narváez, García de Palacio, J. de Urrea, Marcos de Isaba, Sancho de Londoño o B. de Escalante. Vid. la recopilación efectuada al respecto por PudDU, R., Op. cit., págs. 237-283. 
toridades militares de todo tipo de cofradías y asociaciones religiosas o el creciente recurso a celebraciones públicas en forma de bendiciones de banderas, misas de acción de gracias, etc. ${ }^{10}$

Más allá de los testimonios literarios, la realidad individual del soldado resulta mucho menos conocida y obliga a la utilización de indicadores concretos que permitan perfilar con nitidez los principales rasgos de su comportamiento ${ }^{11}$. En relación con la cuestión que nos ocupa, sin duda el tema de la actitud ante la muerte constituye un referente privilegiado, tanto por la primacía alcanzada a nivel historiográfico como por su especial adecuación a las características del grupo social seleccionado. En este sentido, el primero de ambos factores ha de facilitar un análisis comparativo entre sociedad civil y sociedad militar, mientras el segundo actúa reforzando la validez de la muestra, por cuanto en pocos colectivos como el militar se encuentra tan presente el tema de la muerte ${ }^{12}$.

Si los diversos elementos reseñados anteriormente sirven para justificar la pertinencia e interés del objeto de investigación, la elección de La Coruña como ámbito de estudio encuentra también apoyaturas más que suficientes, por cuanto durante la época considerada esta ciudad iba a contar con una guarnición permanente constituida por una o dos compañías, además de jugar un importante papel como base naval y punto de partida de diversas expediciones hacia Inglaterra, Bretaña, Irlanda y Flandes. Pese a tal circunstancia y a la atención que el tema de la actitud ante la muerte ha venido despertando entre los historiadores gallegos de sus últimas décadas ${ }^{13}$, la carencia de investigaciones al respecto otorga carácter de

10 En sentido inverso, también se ha resaltado la creciente influencia militar en el ceremonial religioso mediante la imposición de rígidas normas jerárquicas en el desarrollo de las procesiones, que llegan a ser trazadas como una columna militar mientras incorporan a los oficiales al grueso de los cortejos y a los soldados a la custodia del recorrido. Vid. BEBIANO, R,. "Elementos de un barroco militar", Revista de Historia das Ideias, núm. 11 (1989), págs. 113-125.

11 Esta tarea resulta doblemente necesaria en este caso por cuanto el tema suele solventarse recurriendo a referencias aisladas que conforman un arquetipo más o menos generalizado. A título de ejemplo, la vida y aventuras del capitán Alonso de Contreras y la de Estebanillo González han servido a Marcellín Defourneaux para analizar los cambios de mentalidad y comportamiento de los militares españoles entre la segunda mitad del siglo Xv! y mediados del siglo siguiente. Vid. Defourneaux, M., La vida cotidiana en la España del siglo de oro. Barcelona 1983, págs. 184-204.

12 Amplias consideraciones sobre los distintos aspectos de la muerte militar, sus relaciones con la muerte religiosa y la evolución de sus representaciones artísticas pueden encontrarse en el artículo de CORVISIER, A., "La mort du soldat depuis la fin du Moyen Âge", Révue Historique, T. CCLIV (1975), págs. 3-30. En el caso de España dicha temática resulta especialmente adecuada a juzgar por algunas de las consideraciones extendidas sobre la mentalidad del conjunto de la población. Cfr. Bennassar, B., Los españoles. Actitudes y mentalidad. Barcelona 1976, págs. 222-233.

3 Un análisis pormenorizado de la historiografía gallega más actual puede encontrarse en 
novedad a esta pequeña aportación que se apoya básicamente en el análisis de 130 testamentos datados en la primera mitad del siglo xVII. Aunque tal volumen documental está lejos de poder considerarse plenamente satisfactorio, la inexistencia de un organismo oficial capaz de conformar un fondo homogéneo ha servido para restar eficacia a la labor de recopilación de últimas voluntades ${ }^{14}$. Además, tanto el carácter temprano de la etapa considerada como las condiciones de conservación de los protocolos notariales coruñeses se han aliado para añadir nuevas dificultades a cualquier intento de recogida sistemática de escrituras ${ }^{15}$. El carácter aleatorio de la muestra, por lo tanto, y la inexistencia o el subregistro de los fallecidos con testamento en las diversas parroquias coruñesas nos exime de entrar en la ardua cuestión de la representatividad del documento testamentario, centrando con ello el grueso de las observaciones en la información concreta proporcionada por las fuentes.

El primer elemento de análisis tiene su origen en la propia articulación interna del fondo documental, por cuanto se encuentra constituido por testamentos de militares, pero también se completa con algunos de sus esposas, al considerarlos especialmente útiles para el acercamiento al

los trabajos de REY CASTELAO, O., "Evolución y resultados de los estudios sobre mentalidad y cultura en la Galicia del período moderno» Hispania, L/3, núm. 176 (1990), págs. 1237-1258 y "La muerte en Galicia: actitudes religiosas ante el más alla en el Antiguo Régimen", VI Xornadas de historia de Galicia. Mentalidades Colectivas e Ideoloxias. Ourense 1991, págs. 173-208.

14 En este sentido es preciso señalar que los escasos ejemplos existentes de utilización de documentos testamentarios referidos a militares suelen tomar como punto de partida fondos muy concretos, así por ejemplo G. PARKER pudo consultar 226 testamentos sometidos a examen por la Auditoría General del ejercito de Flandes entre 1604 y 1606 , mientras para el siglo XVIII la existencia de expedientes militares y otras fuentes de carácter especifico vendría a facilitar considerablemente la tarea, concentrando la atención de los historiadores en dicha etapa. Vid. Marchena Fernández, J., Oficiales y Soldados en el Ejercito de América. Sevilla 1983; Gil MUÑoz, M., "Un estudio sobre mentalidades en el Ejército del siglo XVIII (La actitud ante la muerte a través de los testamentos de los oficiales en el reinado de Carlos III)", Cuadernos de Historia Moderna, núm. 10 (1989-90), págs. 121-145 y ANDÚJAR CASTILLO, F., Los militares en la España del siglo XVIII. Un estudio social. Granada 1991. Para el período inmediatamente anterior tan sólo contamos con una breve comunicación presentada al II Congreso Internacional de Historia Militar celebrado en Zaragoza y apoyada en 52 testamentos onubenses. LARA RODENAS, M. J. y GonzÁlez CRUZ, D., “El militar de provincias ante el siglo de las reformas. Una aproximación a su vida familiar, social y económica a través de la documentación testamentaria: cincuenta años en el caso de Huelva (1680-1730)" (texto mecanografiado).

15 Aunque el grueso de los protocolos utilizados procede del Archivo del Colegio Notarial de La Coruña, parte de la documentación se ha recogido también en el Archivo del Reino de Galicia, tratando de completar con ello la trayectoria de los escribanos con representación en ambos centros. Esta circunstancias y el carácter manifiestamente fragmentado de un bueri número de protocolos ha obligado a centrar la atención sobre escribanos muy concretos, prescindiendo de calas o cualquier pretensión de muestreo de carácter general. Aun así hemos llegado a manejar 5.049 escrituras de diverso tipo, lo que indica con claridad la rareza del testamento militar y las dificultades que ello impone a su investigación. 
universo mental del entorno. Además, habría que hacer una distinción elemental entre testamentos de soldados, oficiales y grupos específicos como artilleros, altos miembros de la administración militar (gente del sueldo) y soldados de leva, asegurando con ello la representación de los diversos estratos que componen la sociedad militar ${ }^{16}$. Si la estructuración de la muestra debe adaptarse a las particularidades del ámbito de análisis, el instrumento del mismo también requiere de algunas consideraciones previas. Así habría que señalar inicialmente que la legislación iba a favorecer la redacción de los testamentos de militares con objeto de conocer el modo de disposición de sus bienes en caso de fallecimiento repentino o ante la imposibilidad de efectuarlo estando en campaña. En contrapartida, éstos tenían el privilegio de ver simplificadas las formalidades y requisitos de la escritura, aunque hasta el siglo xvIII la cuestión no iba a verse completamente regulada ${ }^{17}$. En época inmediatamente anterior el fomento de la práctica testamentaria vino dada por la imposibilidad del cobro de sueldos atrasados sin haber designado previamente un legatario, aunque el problema se planteara sobre todo entre los militares desplazados fuera del territorio peninsular ${ }^{18}$. En el caso de guarniciones permanentes como la coruñesa el mayor grado de integración en la sociedad local contribuía a diluir los efectos negativos del alejamiento del entorno familiar, reduciéndose así las diferencias entre la situación del militar y la del resto de sus vecinos. Para verificar este extremo, sin embargo, será preciso descender al análisis particularizado de las cláusulas testamentarias y a su comparación con las de otros grupos mejor conocidos, tarea que trataremos de desarrollar ciñéndonos a los aspectos básicos del documento.

La lectura del centenar de testamentos disponibles viene a poner de manifiesto que algo más del 70 por cien de los testadores que hacen referencia a su «estado de salud» reconocen estar enfermos, porcentaje inferior al de las mujeres de militares -88 por cien-, pero no demasiado divergente con respecto a las proporciones hasta ahora conocidas para Galicia $^{19}$. Esta primera afirmación puede resultar sorpresiva por tratarse

16 En concreto contamos con 57 testamentos de soldados, 22 de oficiales, 4 de artilleros, 5 de "gente de sueldo", 13 de soldados de leva, 13 de mujeres o viudas de soldados, 9 de mujeres de oficiales, 3 de mujeres de artilleros y 4 de mujeres del "gente del sueldo".

17 Un pequeño resumen de la evolución del testamento militar puede encontrase en GIL MuÑoz, M., Op. cit., págs. 124-128.

${ }_{18}$ El caso del ejercito de Flandes podría considerarse especialmente significativo en este sentido dado el gran número de fraudes que rodeaban la práctica del testamento y la escasa calidad moral de los capellanes inicialmente encargados de su administración. Vid. PARKER, G., Op. cit., págs. 215-217.

19 A mediados del siglo XvII (1646-1656) y en el conjunto de la Galicia occidental el 80 por 
de un colectivo teóricamente expuesto a situaciones de riesgo y en consecuencia más susceptible de haber previsto con antelación su última voluntad. Sin embargo, la coincidencia de resultados con algún ejemplo analizado para el siglo XVIII obliga a detenerse algo más en este asunto ${ }^{20}$. $\mathrm{Si}$ se desglosan los porcentajes correspondientes a los diversos sectores militares es posible dar una primera explicación a este hecho, según lo reseñado en la tabla 1.

TABLA 1. ESTADO DE SALUD DEL TESTADOR ${ }^{21}$

\begin{tabular}{lccccc}
\hline & $\mathrm{n} \cdot{ }^{\circ}$ & enfermos & sanos & a embarcar & $?$ \\
\hline Soldados & 57 & 37 & 5 & 7 & 8 \\
& & $(64 \%)$ & $(8,7 \%)$ & $(12 \%)$ & $(14 \%)$ \\
Oficiales & 22 & 17 & 2 & 1 & 2 \\
\multirow{2}{*}{ Soldados leva } & 13 & $(77 \%)$ & $(9 \%)$ & $(4,5 \%)$ & $(9 \%)$ \\
& & $(15 \%)$ & $(7,6 \%)$ & $(46 \%)$ & $(30 \%)$ \\
\hline
\end{tabular}

De la lectura de estas cifras se desprende que no es tanto el nivel jerárquico del individuo como su destino concreto el que determina su mayor o menor disposición a testar. En este sentido la inclusión en la muestra de los levados a Flandes resulta suficientemente ilustrativa, sobre todo al no tratarse de militares de oficio. La comparación entre oficiales y soldados, por otra parte, no ofrece diferencias significativas, salvo el indicio de un mayor grado de sedentarización entre los primeros, lo que cabría poner en relación con la importante presencia de "entretenidos" en el presidio coruñés ${ }^{22}$. Aparentemente, pues, la situación de los militares asentados en la ciudad no presenta grandes divergencias con respecto

cien de los testadores se declaraba enfermo, certificando con ello que la falta de previsión era una tendencia generalizada. Vid. GonzÁLEZ LOPO, D., Mentalidades y grupos sociales en la Galicia del siglo xvil a través de la Documentación de Protocolos. Memoria de licenciatura inédita. Santiago 1981, pág. 39.

20 El 70 por cien de los 288 testamentos de oficiales del reinado de Carlos III analizados por Margarita Gil corresponde también a individuos enfermos en diversos grados, destacando en este sentido que el porcentaje mayor -46 por cien- fuese el de enfermos muy graves, próximos a morir. Cfr. GIL MUÑOz, M., Op. cit., pág. 131.

${ }^{21}$ En la confección de esta tabla hemos suprimido las referencias a los artilleros y la gente del sueldo debido a su escasa representación ( 4 artilleros -2 que no indican nada, 1 enfermo y 1 sano- y 5 miembros de la administración militar -4 enfermos y 1 que no lo indica-).

${ }_{22}$ Los entretenidos eran oficiales en espera de destino, situación en la que podían permanecer durante años adscritos a una guarnición o a un buque. En el caso de La Coruña su abundancia en la primera mitad del XVII llegó a ser motivo de serias preocupaciones por parte de la primera autoridad militar del Reino, como prueban algunas de las cartas remitidas al rey por D. Diego de las Mariñas. Vid. Archivo General de Simancas (AGS), Guerra Antigua (GA), leg. $681, \mathrm{~s} / \mathrm{fol}$. 
al resto de la población, lo que obliga a analizar con especial detenimiento las cláusulas estrictamente religiosas de sus testamentos.

Las fórmulas encomendatorias desarrolladas al inicio de los documentos se caracterizan por presentar escasos rasgos diferenciadores entre ellas y por ajustarse al modelo general de la época ${ }^{23}$. En este sentido resultan mucho más interesantes las referencias a los «intercesores", aun cuando sigamos moviéndonos en reducidos coeficientes de variación. Así, el porcentaje de individuos que señalan intercesor resulta elevado -60 por cien-, mostrándose acorde con el de mujeres de militares -58 por cien-, aunque algo inferior a los predominantes en la sociedad civil ${ }^{24}$. Lo mismo cabría decir de su identidad, dado el abrumador predominio de las referencias a la Virgen - casi el 80 por cien de los casos-y el papel secundario otorgado a la corte celestial -15 por cien-. Frente a esta realidad, la escasa representación de santos indicadores de una devoción particular se constituye en un rasgo distintivo que posiblemente quepa atribuir más al carácter temprano de la muestra que a la condición de militares de los otorgantes ${ }^{25}$. En concreto sólo en tres de los testamentos correspondientes a soldados se incluye una referencia de ese tipo, mientras en los de mujeres de militares no aparece ninguna ${ }^{26}$.

A priori la disposición de los ritos funerarios ha de resultar más significativa en orden a establecer diferencias entre sociedad militar y socie-

${ }^{23}$ En el capítulo de las invocaciones a mediados del siglo xvII la tendencia predominante en Galicia incluía la profesión de fe completa, la encomendación del alma y la presencia de intercesores. Vid. GONZÁLEZ LOPO, D., "La actitud ante la muerte en la Galicia occidental de los siglos XVII y XVIII's, en La documentación notarial y la historia. Actas del II Coloquio de Metodología Histórica aplicada. Santiago de Compostela 1984, vol. II, pág. 135

Las encomendaciones, a su vez, parecen caracterizarse por su uniformidad, circunstancia de la que eran partícipes todos los grupos sociales a juzgar por el caso del clero urbano, que pese a gozar de un mayor nivel cultural que el resto de la población no iba a introducir modi. ficaciones en las innovaciones religiosas tradicionales. Vid. REY CASTELAO, O., «El clero urbano compostelano a finales del siglo XVII: mentalidades y hábitos culturales", en EIRAS ROEL, A. et alli., La Historia Social de Galicia en sus fuentes de Protocolos. Santiago 1981, págs. 496-497.

${ }_{24}$ Así por ejemplo en la década 1646-1656 el 82,61 por cien de los testamentos santiagueses analizados por Domingo González señalan intercesor. Vid. González LOPO, D., Mentalidades..., pág. 75 .

${ }_{25}$ Téngase en cuenta que el recurso a la mediación de intercesores se irá incrementando en el transcurso del siglo XVII tras un punto de partida en el siglo anterior marcado por la prácticamente exclusiva referencia a la Virgen. Sobre la situación de Galicia vid. González LoPo, D., "La actitud ante la muerte...", pág. 135.

${ }^{26}$ De esos tres casos uno alude a la Virgen y a S. Francisco (testamento de Francisco González, fechado el 30/XI/1609), otro a la Virgen y Sta. Catalina (testamento de Juan Trincado de Robleda, del $22 / X / 1610$ ) y el tercero a la Virgen y Santa Ana (testamento de Juan Pérez de Vivero, del 16/IV/1629). Vid. Archivo Colegio Notarial de La Coruña (ANC), leg. 478, fol. 54; leg. 374 , fol. 389 y leg. 591 , fol. 202. 
Algunos rasgos del comportamiento religioso de los militares españoles...

dad civil que las invocaciones, sobre todo por lo que se refiere a la regulación del lugar de sepultura y del ceremonial fúnebre. La elección de mortaja también puede aportar algunos indicios en el mismo sentido, aunque sólo en el 29 por cien de los casos se aluda a este asunto. Este bajo porcentaje nuevamente podría ponerse en relación con el período cronológico de referencia, si bien los datos conocidos para etapas posteriores inducen a considerar este hecho como una peculiaridad de los estamentos militares ${ }^{27}$. Significativamente, ninguno de los soldados de leva incluye este dato en sus testamentos, que se caracterizan por estar más inclinados a extenderse en el apartado de disposición de bienes y cobro de deudas que en los aspectos puramente religiosos, lo que vuelve a apuntalar la idea de que es el destino inmediato del militar y no su condición de tal lo que determina su actitud en este terreno. ${ }^{28}$ La tipología de los hábitos señalados exige también de algún comentario, pues no en vano en el 62 por cien de los casos se corresponde con el hábito de S. Francisco, mientras el 38 por cien restante incluye el de Sto. Domingo ${ }^{29}$. Esta circunstancia sí supone una diferencia clara con respecto a la situación general de la época, marcada por el abrumador predominio del primero, y encuentra su complemento en el hecho de que más del 40 por cien de las mujeres de militares que indican mortaja señalen precisamente el habito de Sto. Domingo ${ }^{30}$. Aunque tal distorsión pueda considerarse poco significativa dado el reducido tamaño de la muestra, el análisis de los

27 Sólo en el 45 por cien de los testamentos de oficiales analizados para el reinado de Carlos III se recoge la solicitud de mortaja y de ellos el 22 por cien dejan la elección en manos de la esposa y el 6 por cien de los albaceas. Cfr. GIL Muñoz M., Op. cit., pág. 136. En cualquier caso, es necesario reconocer que en la primera mitad del siglo xvIl las referencias a la mortaja en los testamentos civiles no eran muy abundantes, habiéndose iniciado entre los grupos privilegiados el movimiento tendente a amortajar difuntos que progresivamente se iría extendiendo a todos los sectores sociales. Según el estudio de D. González, en 1628 sólo el 1/3 de los testadores localizados en la ciudad de Santiago la solicitan, porcentaje elevado al 47,8 por cien para el período 1646-1656. Vid. GonZÁLEZ LOPO, D., "La actitud...", pág. 127.

28 A título de ejemplo valga el caso de Diego de Prada, vecino de la tierra de Valdeorras, quien el 18/1/1640 hacía su testamento en La Coruña antes de embarcar en la armada real. Salvo la encomendación a “Dios nuestro Señor" y la ofrenda de $10 \mathrm{mrs}$. a la Sta. Cruzada y otros $10 \mathrm{mrs}$. a los lazarados, el resto del documento alude a las deudas con él contraidas por algunos de sus vecinos para concluir nombrando por heredera de las mismas a su hermana. Archivo del Reino de Galicia (ARG), Protocolos, núm. 398, s/fol.

${ }_{29}$ Significamente, no hemos encontrado ningún ejemplo en el que se solicite el enterramiento con uniforme y sólo uno en el que se señala otra posibilidad. Corresponde éste al capitán de origen portugués Cristobal Márquez de Fonseca, quien solicita un hábito de S. Francisco y por debajo "el hábito de Cristo de que soy caballero y con espada". ACN - leg. 408, s/fol.

3o Así para la ciudad de Santiago se han señalado porcentajes de utilización del hábito de $S$. Francisco superiores al 80 por cien (en concreto, del 84,31 por cien entre $1551-1560$ y del 87,95 por cien entre 1651 y 1660). Vid. GonZÁLEZ LOPO, D., "La mortaja religiosa en Santiago entre los siglos XVI y XIX», Compostellanum, vol. XXXIV, núm. 3-4 (1989), págs. 271-295. 
demás aspectos que componen el rito funerario añade nuevos elementos explicativos a la misma y obliga a considerarla como algo más que el fruto de la casualidad. En este sentido la elección del lugar de enterramiento resulta suficientemente ilustrativa sobre el particular, tal y como refleja la tabla 2 .

TABLA 2. LUGAR DE SEPULTURA

\begin{tabular}{lccccc}
\hline & n. & parroquia & S. Franc. & Sto. Dom. & $?$ \\
\hline Soldados & 57 & 8 & 13 & 32 & 4 \\
Oficiales & 22 & $(14 \%)$ & $(22,8 \%)$ & $(56 \%)$ & $(7 \%)$ \\
& & 1 & 13 & 6 & 2 \\
Levados & 13 & $(4,5 \%)$ & $(59 \%)$ & $(27 \%)$ & $(9 \%)$ \\
& & 5 & 0 & 1 & 7 \\
Artilleros & 4 & $(38 \%)$ & 0 & $(7,6 \%)$ & $(53 \%)$ \\
G. sueldo & 5 & 2 & 1 & 1 & 0 \\
\hline
\end{tabular}

A primera vista el dato más llamativo de esta tabla es el absoluto predominio del enterramiento en conventos frente a la mayor tendencia de la sociedad civil hacia la sepultura en la propia parroquia ${ }^{31}$. Nótese a este respecto las diferencias impuestas por los soldados de leva, quienes no sólo parecen dedicar menos atención a este asunto, sino que también resultan los más inclinados al enterramiento parroquial. Tal circunstancia no hace más que apuntalar lo señalado hasta este momento sobre la parquedad de sus testamentos y su mayor sintonía de comportamientos con el cuerpo social en su conjunto. Por lo que se refiere a los militares estrictamente profesionales, la preferencia por los conventos parece ser una constante que pervive en el tiempo y que ha de ponerse en relación con el predominio de solidaridades internas frente a los vínculos de tipo vecinal. ${ }^{32}$ En este sentido resulta muy útil el acercamiento a los testamentos de las mujeres de militares, en tanto que éstas designan en proporciones muy similares parroquias (48 por cien) y conventos (45 por cien) como lugar de sepultura, 10 que refleja su posición intermedia entre la sociedad civil y la sociedad militar.

31 En este sentido cabe destacar que precisamente la población de tipo medio y acomodada de las ciudades constituye el sector en el que se registra una mayor proporción de enterramientos en conventos. Vid. GonzÁlez Lopo, D., Mentalidades..., pág. 132.

32 En el caso ya citado de los oficiales del reinado de Carlos III nos encontramos frente a un 24,8 por cien de ellos que señalan como lugar de enterramiento la parroquia, un 61 por cien que se inclina hacia conventos, parroquias catrenses, iglesias, hospitales y catedrales. A señalar igualmente que en ningún caso se solicita el enterramiento en el lugar de origen. Cfr. GiL Muñoz, M., Op. cit., pág. 137. 
La disposición del acto del entierro propiamente dicho arroja nuevos datos de interés a lo expuesto hasta este momento, sobre todo por lo que se refiere a la cuestión de la solidaridad del colectivo militar. El repaso al número y variedad de cofradías señaladas por los testadores para su acompañamiento constituye el referente básico en este apartado, poniendo de manifiesto la eficacia de la labor de fomento del asociacionismo religioso desarrollada en el seno del ejército hispano. De hecho, más de la mitad de los otorgantes solicitan el acompañamiento de alguna cofradía, estableciéndose nuevamente una diferencia clara entre los militares de oficio (lo señalan el 63 por cien de los oficiales y soldados) y los levados, que dada la cortedad de sus testamentos y la incertidumbre acerca del lugar de fallecimiento no hacen referencia a esta cuestión. Significativamente, es la cofradía de la propia compañía la elegida en la práctica totalidad de las ocasiones, aunque se recurra además a otras asociaciones y al acompañamiento de los frailes de los conventos de $S$. Francisco y Sto. Domingo ${ }^{33}$. La adscripción a estos edificios conventuales de las cofradías castrenses explica la estrecha vinculación existente entre los militares y las órdenes mendicantes que estaban obligadas a asistir a sus entierros, y sobre todo en el caso de los franciscanos, quienes además servían como capellanes de las compañías residentes en la ciudad ${ }^{34}$. Por lo que se refiere a los testamentos de las mujeres, resulta muy interesante comprobar cómo la mitad de las que solicitan acompañamiento recurren a la cofradía de la compañía del marido, mientras la otra mitad opta por las cofradías parroquiales y los frailes de los conventos de la ciudad. Aunque la muestra es demasiado reducida como para extraer de sus datos referencias concluyentes, podríamos volver a insistir en su mayor grado de vinculación con el entorno vecinal. En defensa de esta aseveración cabe hacer referencia al apartado de las ofrendas fúnebres, pues no en vano mientras tan sólo siete militares la dejan ordenada, son nueve las mujeres que hacen to mismo pese a que el número de sus testamentos es mucho menor ${ }^{35}$.

${ }^{33}$ En este sentido, se observa un claro paralelismo con el comportamiento de otros colectivos juridicamente privilegiados, como el clero, según se desprende del análisis realizado por Ofelia Rey para el caso santiagués. En este ejemplo la cofradía de la Concepción de los clérigos aparece reseñada en el 85,7 por cien de los testamentos del grupo, constando expresamente como cofrades el 67 por cien de los testadores. Dicha cofradía iba a actuar, en consecuencia, como elemento aglutinador del conjunto del clero, superando con ello los niveles jerárquicoa existentes en el mismo. Vid. Rey CASTELAO, O., "El clero urbano...”, pág. 498.

${ }^{34}$ Los capellanes debían confesar a los soldados en Cuaresma y en los momentos de enfermedad y a decir misa en el fuerte de $S$. Antón los domingos y festivos. Vid. Pazos, M., "Cofradías piadosas y capellanías castrenses en el convento de San Francisco de La Coruña (siglo xVI y XVII), Boletín de la Real Academia Gallega, núm. 24. (1945), págs. 423-437.

${ }_{35}$ En concreto se trata de dos soldados que mandan aceite y cera para el Santísimo Sa- 
El diverso grado de sensibilidad religiosa entre hombres y mujeres y la penuria económica de los militares son algunas de las razones que pueden aducirse para explicar la escasez de ofrendas, si bien es preciso reconocer que dicha práctica no había de gozar nunca de gran predicamento entre la población. En cualquier caso, la lectura del capítulo de sufragios ha de aportar datos más sustanciales sobre este asunto, perfilando con ello el nivel de disponibilidades monetarias de los miembros del ejército. El primer rasgo a destacar sería el abrumador predominio de las «misas por una vez» frente a las fundaciones de misas y ello pese a tratarse de un período temprano ${ }^{36}$. Junto a esta circunstancia, resulta digno de mención igualmente el porcentaje de individuos que especifican el número de misas a celebrar, pero sobre todo la frecuencia con la que dichos mandamientos se acompañan de la expresión "si hubiere con que", bien indicativa de la fragilidad de su situación económica ${ }^{37}$. Si tomamos en consideración el número de misas estipuladas en los testamentos, tal extremo se refleja en toda su crudeza, tal y como pone de manifiesto la tabla 3 .

cramento de su parroquia, un oficial que deja la ofrenda a voluntad de los cumplidores, otro que señala 20 reales y un tercero que alude a su satisfacción "conforme a mi posibilidad que al presente es poca", además de un miembro de la administración militar que también la deja a voluntad de sus cumplidores y un artillero que señala "6 ducados en pan, vino, cera y carne". Por lo que se refiere a las mujeres, dos esposas de soldados y dos de oficiales la dejan a voluntad de los cumplidores, tres mujeres de oficiales estipulan una cantidad de dos ducados y otras dos señalan algunos otros productos a mayores. Así María García, mujer del alférez Roque Rodríguez, manda de ofrenda al cura de la parroquia 6 ducados "y si no se contentare con ello le mando una anega de trigo, un carnero, doce azumbres de vino y cuatro libras de cera...", mientras doña Catalina Bermúdez de Castro, esposa del castellano del fuerte de S. Antón D. Juan Pardo Osorio, señala una ofrenda de 150 rs. al rector de su parroquia y otra de dos cargas de trigo de a 12 ferrados y 12 achas de cera al convento de S. Francisco. Vid. ARG, Pleitos, núm. 433, f.32 y ARG, Protocolos, núm. 468, s/fol.

${ }_{36}$ En este sentido es preciso hacer constar que la primera mitad del siglo xvil generalmente se considera como el período de mayor florecimiento de las fundaciones de misas, a partir del cual su presencia se iria reduciendo progresivamente en beneficio de las misas por una vez. $A$ título de ejemplo, valga el aportado por Baudilio Barreiro, según el cual el 71,2 por cien de las misas perpetuas celebradas en la parroquia de Sta. María del Camino de Santiago corresponde a fundaciones efectuadas entre 1550 y 1560 . Vid. BARREIRO MALLÓN, B., «El sentido religioso del hombre ante la muerte en el Antiguo Régimen. Un estudio sobre archivos parroquiales y testamentos notariales", I Jornadas de metodología aplicada de las ciencias históricas. Santiago 1975, T.V., págs. 181-197.

${ }_{37}$ En este caso los soldados estipulan el número de misas en un 65 por cien de los casos, los oficiales en el 54,5 por cien y los soldados de leva en un 77 por cien, marcando así un claro contraste con la situación dieciochesca. (Sólo el 40 por cien de los testamentos de oficiales analizados por Margarita Gil indican el deseo de sufragios, lo cual es interpretado como el resultado de la falta de medios de los otorgantes o la amplia confianza depositada en la esposa y en los albaceas. Vid. GIL Muñoz, M., Op. cit., pág. 140. 
Algunos rasgos del comportamiento religioso de los militares españoles...

TABLA 3. MISAS POR UNA VEZ

\begin{tabular}{lccc}
\hline \multicolumn{1}{c}{ Núm. misas } & soldados & oficiales & levados \\
\hline Hasta 25 & 21 & 4 & 8 \\
26 a 50 & 8 & 5 & 2 \\
51 a 75 & 4 & 0 & 0 \\
76 a 100 & 4 & 1 & 0 \\
Más 100 & 0 & 2 & 0 \\
\hline
\end{tabular}

Inicialmente el resultado de la prospección entra dentro de lo previsible al marcar una clara diferencia de comportamiento entre los estratos inferiores del estamento militar y el grupo de oficiales. Pese a esta divergencia de partida, la mediocridad viene a ser una característica común a todos ellos, tanto si se comparan con los datos conocidos para la sociedad civil como si se analizan de forma aislada, pues no en vano tan sólo dos oficiales superan las cien misas y uno de ellos lo hace en una cantidad insignificante (104 misas) ${ }^{38}$. Aunque en la tabla 3 no se han incluido referencias a los artilleros, a la gente del sueldo y a las mujeres de militares dado lo reducido de su representación, la consulta de sus testamentos en nada modifica el panorama de conjunto, salvo algún caso aislado de carácter totalmente excepcional ${ }^{39}$. Mucho más significativo resulta, en este sentido, la frecuencia con la que se incluyen en los testamentos nuevas mandas de misas ofrecidas "del sueldo que S.Magd. me debe", circunstancia que aparece entre los soldados en un total de 14 casos y 4 entre ia oficialidad, volviendo a certificar así su debilidad económica ${ }^{40}$. Dicho esto, poco cabe esperar del capítulo de fundaciones de misas, concretado en media docena de ejemplos que se caracterizan por tratarse de aniversarios que se fundan en la feligresía de procedencia del militar y con el respaldo material de la legítima de sus ascendientes ${ }^{41}$. Esta realidad

38 A este respecto resulta sumamente útil la consulta de las cifras publicadas para Santiago, ciudad en la que el número medio de misas solicitadas por los grupos más humildes de la población en el período 1646-1656 iba a ser de 56, cantidad que casi se duplica entre los sectores medios y que contrasta ampliamente con los datos obtenidos en nuestro caso. Cfr. GONZÁLEZ LOPO, D., "La actitud...”, pág. 131.

${ }^{39}$ En concreto nos referimos al testamento de doña Catalina Bermúdez de Castro, esposa de D. Juan Pardo Osorio, caballero del hábito de Santiago y castellano del fuerte de S. Antón de La Coruña, en el que se solicita la celebración de 2.000 misas los días del entierro, honras y aniversario, la mitad de las cuales habian de decirse en el convento de Sto. Domingo y la otra mitad en el de S. Francisco. ARG, Protocolos, núm. 468, s/fol.

40 El retraso de varios años en el pago de salarios a los militares era una realidad habitual en el ejército español, circunstancia que no iba a ser tanto causa de motines como estímulo para el ejercicio de todo tipo de trabajos por parte de los soldados. Vid. THOMPSON, I.A.A., Guerra y decadencia. Gobierno y administración en la España de los Austrias, 1560-1620. Barcelona 1981, págs. 85-125.

${ }^{41}$ Las referencias reunidas corresponden a tres soldados - Juan Trincado, que funda un 
y la ausencia de un comportamiento diferenciado entre oficiales y soldados vuelve a incidir en esa imagen general de mediocridad a la que nos hemos venido refiriendo hasta aquí y cuya prolongación natural debería de encontrarse en el último apartado estrictamente religioso de los testamentos, el correspondiente a los legados píos y a las mandas forzosas. Por lo que se refiere a los primeros, cabe destacar su relativa frecuencia - 29 casos entre los soldados (50 por cien), 9 entre los oficiales (41 por cien) y 5 entre los levados (38 por cien)-, lo que equipara su situación a la de grupos sociales especialmente proclives a este tipo de caridad, ${ }^{42}$ aunque mucho más llamativo resulte el valor de los mismos, según se recoge en la tabla $n .^{\circ} 4$

TABLA 4. LEGADOS PÍOS

\begin{tabular}{lccc}
\hline \multicolumn{1}{c}{ Valor (rs.) } & soldados & oficiales & levados \\
\hline Hasta 5 & 9 & 2 & 5 \\
de 6 a 50 & 4 & 0 & 0 \\
de 51 a 100 & 2 & 0 & 0 \\
de 100 a 500 & 3 & 3 & 0 \\
más de $1000^{43}$ & 10 & 2 & 0 \\
Paga sueldo & 1 & 2 & 0 \\
\hline
\end{tabular}

A primera vista la entidad de los legados resulta totalmente desproporcionada con respecto a la situación de los militares que dibujan el resto de las cláusulas testamentarias. Si a ello añadimos la alta proporción de individuos que señalan mandas pías, nos encontramos ante un acusado contraste de comportamiento entre la población militar y la población civil $^{44}$. La clave explicativa del mismo se ha avanzado ya en el apartado

aniversario de 3 misas, Juan Fernández, de dos, y Pedro Fernández, también de dos- un oficial, Juan Vázquez de Montes, que funda una misa anual, y un mareante coruñés sujeto a leva, Antonio de S. Pedro, que también funda una misa anual. (Vid. respectivamente ACN, leg. 374, f. 389; leg. 589 , f. 49 ; leg. 478 , f. 34 ; leg. 405 , f. 48 y leg. 390 , s/fol.) En total vendrian a representar el 6 por cien de los testadores, porcentaje que contrasta con los registrados en la sociedad civil (entre 1646 y 1656 el 49 por cien de los testamentos localizados en Santiago disponian de misas de fundación), pero que se muestra más acorde con la situación de los oficiales del reinado de Carlos III, quienes sólo disponen de fundaciones en 10 casos sobre un total de 288. VID. GIL MUNOZ, M., Op. cit., pág. 142.

${ }_{42}$ Así en el 50 por cien de los testamentos de los clérigos santiagueses de finales del siglo XVII aparecian también legados piadosos, lo que ha sido considerado un porcentaje elevado. Vid. ReY CASTELAO, O., "El clero urbano...", pág. 501.

${ }_{43}$ En concreto las cantidades estipuladas son: en el caso de los soldados tres legados de 1.500 rs. y los demás de 1.225 rs., 2.110 rs., 2.250 rs., 2.710 rs., 6.800 r.s y hasta uno de 30.000 rs. Por lo que se refiere a los oficiales, los tres ejemplos que superan los 1.000 r.s corresponden a 1.500 rs., 9.000 rs. y 20.000 rs.

${ }^{44}$ Téngase en cuenta que el mayor legado localizado por Domingo González en Santiago a mediados del siglo Xvil era de 30 reales y aún en el caso del clero se caracterizaban por su 
anterior, cuando hacíamos referencia al gran número de misas señaladas con cargo al sueldo adeudado. También en este caso la mayor parte de los legados aparecen cargados sobre el sueldo, salvo los correspondientes a las cantidades más pequeñas. La divergencia existente entre los legados de los militares profesionales y los levados corrobora igualmente dicha hipótesis que se apoya tanto en la acumulación de deudas por parte de la administración militar como las dificultades existentes para su cobro ${ }^{45}$. El destino de la acción caritativa de los militares, por otra parte, vuelve a incidir en la solidaridad inherente a dicho colectivo, al ser la cofradía de la propia compañía la principal beneficiada de los legados, seguida a gran distancia por los conventos de S. Francisco y Sto. Domingo, las fábricas de iglesias y los hospitales de la ciudad. Esta circunstancia contribuye a explicar las divergencias de comportamiento registradas con respecto a las mandas forzosas, cuya presencia está garantizada en la práctica totalidad de los testamentos militares, pero en cantidades tan reducidas que en nada justifican la imagen del soldado caritativo diseñada en el apartado anterior.

A modo de resumen, el análisis de los testamentos militares que hemos venido efectuando a lo largo de estas páginas parece difuminar la brecha teóricamente existente entre la mentalidad de este colectivo y la del resto de la población, al menos en el terreno de la actitud ante la muerte. En este sentido, las diferencias de comportamiento registradas entre ambos grupos parecen provenir básicamente de la propia situación material de los miembros del ejército hispano. Bien es verdad que el ámbito de análisis - una guarnición permanente- es en buena medida determinante del resultado final, como también lo es la base material del estudio - el testamento-, cuyo formalismo puede constituirse en un elemento distorsionador del mismo ${ }^{46}$. La distancia existente entre el comportamiento del

cortedad, reducidos generalmente al mínimo necesario para alcanzar determinadas indulgencias. Vid. González LOPO, D., “La actitud...”, pág. 133 y Rey CASTELAO, 0., “El clero...”, pág. 502.

${ }_{45}$ Aunque cabría pensar igualmente que el desarraigo de los militares fuese un factor decisivo a la hora de estimular legados de tal cuantía, la lectura de los testamentos disponibles obliga a desechar tal posibilidad, en tanto que la mayor parte de los militares tienen familia directa a la que dejar los bienes (de los 57 soldados que testan 27 dejan como herederos a los hijos, 16 a la esposa, 2 a los hermanos, 1 a los sobrinos, 9 al alma y 2 a otros soldados).

${ }_{46}$ Significativamente, cuando dicho formalismo se supera es posible encontrar algunos de los rasgos arquetípicos de la mentalidad militar descritos por los tratados de la época. ¿Qué mejor ejemplo de caridad cristiana que la actitud del capitán Cristóbal Márquez de Fonseca al dejar como parte de los beneficiarios de sus mandas de misas a "de los de Bretaña a quien hizimos algun daño", suplicando con ello "a su divina magestad me perdone los pecados que en razón de lo susodicho he cometido". ¿Habria alguna manifestación mejor de la austeridad militar que el caso del veedor Manuel de Espinosa, quien en el momento de redactar su última voluntad debe suplicar al rey alguna merced para su familia «por quedar mui pobre a causa de 
militar a nivel individual y la regulación oficial de las prácticas religiosas en el seno del ejército viene a constituirse así en una cuestión difícil de aprehender y cuyo estudio exige una investigación pormenorizada, capaz de ofrecer una respuesta firme a muchas de las cuestiones que en el presente trabajo sólo se esbozan.

la limpieza con que ha servido a S.Magd."? Vid., respectivamente, ACN, leg. 408, s/fol y leg. 380, f. 322 . 